\title{
Sonomorphology and colour flow Doppler studies in differentiating between benign and malignant ovarian masses
}

\author{
Shyamala Jothy M.*, Anju Padmasekar
}

\begin{abstract}
Department of Obstetrics and Gynecology, RajaMirasudhar Hospital, Government Thanjavur Medical College,
\end{abstract} Thanjavur, Tamilnadu, India

Received: 03 December 2016

Accepted: 28 December 2016

\section{*Correspondence:}

Dr. Shyamala Jothy M.,

E-mail: drmsjothy@gmail.com

Copyright: (C) the author(s), publisher and licensee Medip Academy. This is an open-access article distributed under the terms of the Creative Commons Attribution Non-Commercial License, which permits unrestricted non-commercial use, distribution, and reproduction in any medium, provided the original work is properly cited.

\begin{abstract}
Background: Ovarian cancer is the most frequent cause of death from Gynaecological malignancies in the world. Most patients with epithelial ovarian cancer are asymptomatic in early stage disease and usually present with stage III or IV disease. There are various screening methods for detection of ovarian cancer like bimanual pelvic examination, ultrasound examination (TVS and TAS) with or without color Doppler flow imaging and measurement of various circulating proteins like CA 125. The Purpose of a study is to determine optimal cut off point for a morphological scoring system and color flow directed Doppler values to differentiate benign and malignant ovarian masses.

Methods: This study was done at Department of obstetrics and Gynaecology, Government Rajah Mirasudhar Teaching Hospital attached to Government Thanjavur Medical College, Thanjavur, Tamilnadu, India during the period of June - 2011 to October - 2012. This study consisted of 73 patients, 3 patients were not operated as they were not fit for surgery for medical reasons. Hence 70 patients were included in the study. A note was made of their main symptoms at admission, Parity, menopausal status, family history of carcinoma. Patients admitted with diagnosis of ovarian masses and clearly ovarian by sonomorphology and surgery were only included in this study. Morphological Score, RI and PI were calculated. All patients underwent exploratory laparotomy with surgical removal of the tumor. The final diagnosis obtained based on HPE were classified as either benign or malignant. The score of each mass and the Doppler values were assessed individually and in combination with regard to its relationship to final diagnosis.

Results: In summary the resistance to flow measurement obtained by Doppler had a higher sensitivity and specificity compared to the morphological scoring system in differentiating benign and malignant ovarian masses. The combination of morphological score and Doppler Measurements improved the specificity positive predictive value for differentiating benign and malignant ovarian masses.

Conclusions: The combination of ultrasound and Doppler values is better in differentiating benign from malignant ovarian masses. The cut off point for ultrasound guided morphological scoring system was 4 and Doppler velocimetry for differentiating benign and malignant ovarian masses was a RI of 0.55 and PI of 0.8
\end{abstract}

Keywords: HPE, PI, RI, Ultrasonography

\section{INTRODUCTION}

Ovarian cancer is the most frequent cause of death from gynaecological malignancies in the world. Ovarian cancer has a prevalence of $50 / 100,000$ and an annual incidence rate of $14 / 100,000$. Despite advances in treatment and attempts at early diagnosis, long term survival is bleak, with only $40 \%$ of patients surviving 5 years. A women's risk of having ovarian cancer ${ }^{4}$ at birth in her life is $1-1.5 \%$ and dying from ovarian cancer is 
$0.5 \%$. Most patients with epithelial ovarian cancer are asymptomatic in early stage disease and usually present with stage III or IV disease. Their 5yr survival is $<25 \%$. The minority of patients discovered with early stage disease have 5year survival rate of $80-90 \%$. There are various screening methods ${ }^{15}$ for detection of ovarian cancer like bimanual pelvic examination, ultra sound examination (TVS and TAS) $)^{3,5,7,10,23,28,30}$ with or without colour Doppler flow imaging $2,11-13,17,19,22,25,27,29$ and measurement of various circulating proteins like CA $125^{1,6,8,20}$ In analyzing the screening test by measuring CA 125 level and performing transvaginal ultrasound examination $^{26}$ appears to provide the highest specificity and positive predictive value for the detection of ovarian cancer.

The aim of the study was to determine optimal cut off point for a morphological scanning system and colour flow directed Doppler values to differentiate benign and malignant ovarian masses and to evaluate the above methods in differentiating benign from malignant ovarian masses.

\section{METHODS}

This study was done at RMH Thanjavur during the period of June 2011 to November 2012. This study is a prospective study. This study consisted of 73patients, 3 patients were not operated as they were not fit for surgery for medical reasons. Hence 70 patients were included in the study (3-bilateral). A note was made of their main symptoms at admission, parity, menopausal status, family history of carcinoma.

\section{Inclusion Criteria}

Patients admitted with diagnosis of ovarian masses and clearly ovarian by sonomorphology and surgery were only included in this study.

\section{Exclusion Criteria}

- Ovarian masses in pregnant women - as low RI associated with pregnancy may alter the RI on Doppler.

- $\quad$ Patients beyond the $10^{\text {th }}$ day of menstrual cycle - as low resistance flow of corpus luteum may mimic that it is associated with malignant neoplasms (Table 1).

- Transabdominal Doppler using a Toshiba machine with a $3-5 \mathrm{mHz}$ as performed on all these patients after preliminary ultrasound. CFM was used to identify vessels in the tumor. Then the sampling point is identified and spectral waveforms of the vessels and several measurements like peaksystolic and end diastolic velocity from the wall, septum, papillations (if present), solid focus (or) echogenic core were taken. RI and PI were calculated. The lowest value obtained was included in the study.

- All patients underwent exploratory laparotomy with surgical removal of the tumor. The final diagnosis obtained based on HPE was classed as either benign or malignant. Borderline tumors were considered malignant. The score for each mass and the Doppler values were assessed individually and in combination with regard to its relationship to the final diagnosis.

\section{RESULTS}

It is evident that there is a significant difference in the mean values of benign (2.40) and malignant (4.87) ovarian tumors, but the range of score values was similar. This suggests that some of the benign tumor score is high while a few malignant tumors had low scores. 93\% $(58 / 62)$ of benign tumors had score $<4$ while $75 \%(6 / 8)$ of malignant tumors had score $\geq 4.80 \%(50 / 62)$ of benign tumors had score $<3$ while $87.5 \%$ (7/8) of malignant tumors had score $\geq 3$. Hence it is evident that most of the benign tumors had score in lower range and most malignant tumors in the higher range.

Table 1: Morphological score.

\begin{tabular}{|lllll|}
\hline Parameter & 0 & 1 & 2 & 3 \\
\hline Wall structure & $\begin{array}{l}\text { Smooth/small irregularities } \\
3 \mathrm{~mm}\end{array}$ & - & Solid & $\begin{array}{l}\text { Papillary } \\
\text { Projection }>3 \mathrm{~mm} .\end{array}$ \\
\hline Shadowing & Present & absent & - & - \\
\hline Septae & None (or) thin $<3 \mathrm{~mm}$ & Thick $>3 \mathrm{~mm}$ & - & - \\
\hline Echogenicity & $\begin{array}{l}\text { Sonolucent (or) low level echoes } \\
\text { or echogenic core* }\end{array}$ & - & - & Mixed (or) high \\
\hline
\end{tabular}

Total score range between $0-8$. *Includes echogenic masses such as mature cystic teratoma.

Table 2: Score value.

\begin{tabular}{|llll|}
\hline HIPE & No. & Range of score values & Mean \\
\hline Benign & 62 & $0-7$ & 2.40 \\
\hline Malignant & 8 & $1-8$ & 4.87 \\
\hline
\end{tabular}

Using the cut off value of $\geq 3,1 / 8$ malignant masses were rightly identified but 22/62 benign masses were wrongly diagnosed as malignant. Using the cut off value of $\geq 4$, 6/8 malignant masses were correctly identified while only 12/62 benign masses were considered malignant. 
Table 3: Distribution of USG score in benign and malignant ovarian lesions.

\begin{tabular}{|lll|}
\hline Score value & $\begin{array}{l}\text { No. of benign } \\
\text { tumors (HPE) }\end{array}$ & $\begin{array}{l}\text { No. of malignant } \\
\text { tumors (HIPE) }\end{array}$ \\
\hline 0 & 0 & 0 \\
\hline 1 & 15 & 0 \\
\hline 2 & 25 & 1 \\
\hline 3 & 10 & 1 \\
\hline 4 & 8 & 2 \\
\hline 5 & 3 & 2 \\
\hline 6 & 1 & 0 \\
\hline 7 & 0 & 2 \\
\hline 8 & 0 & 0 \\
\hline & 62 & 8 \\
\hline
\end{tabular}

Overall, malignant tumors demonstrated low resistance flow than benign tumors. Mean RI for malignant tumors was 0.42 with range of $0.28-0.72$. mean RI for benign tumors was 0.67 with range of $0.2-1$. Mean PI for malignant tumors was 0.67 with range $0.33-1.15$. Mean PI for benign tumors was 1.2 with range of 0.4 to 1.8 .

Table 4: Comparison of performance of score value >4OR > 3IN predicting malignancy.

\begin{tabular}{|lll|}
\hline & $>3$ & $>4$ \\
\hline Sensitivity & 96.3 & 92.6 \\
\hline Specificity & 66 & 77.27 \\
\hline Positive predictive value & 63.4 & 71.4 \\
\hline Negative predictive value & 96.7 & 94.44 \\
\hline False positive & 34 & 22.7 \\
\hline False negative & 3.7 & 7.4 \\
\hline
\end{tabular}

Table 5: Doppler values of benign and malignant tumors.

\begin{tabular}{|llll|}
\hline Doppler values & Range & Mean \\
\hline RI & Benign & $0.2-1$ & 0.67 \\
\hline & Malignant & $0.28-0.72$ & 0.42 \\
\hline PI & Benign & $0.4-1.8$ & 1.2 \\
\hline & Malignant & $0.33-1.15$ & 0.67 \\
\hline
\end{tabular}

\section{DISCUSSION}

\section{Statistical analysis of resistive index}

Of 70 cases, the mean RI values ${ }^{9,19}$ for benign tumor and malignant tumor was 0.67 and 0.42 .A statistically significant $\mathrm{P}$ value $<0.05$ was obtained for RI value. Based on receiver operating characteristics curve(ROC) with area under curve of $95 \%$ confidence interval RI of 0.55 and 0.6 has optimal sensitivity and specificity and the best cut off for RI was 0.55 which gave a sensitivity of $96.29 \%$, specificity $84.04 \%$, positive predictive value $78.79 \%$ and negative predictive value $97.37 \%$ (Table 6). With a previously proposed RI value of 0.4 , the sensitivity and specificity of malignant tumors in our population were $20 \%$ and $95 \%$.

Table 6: RI values of benign and malignant tumors.

\begin{tabular}{|l|l|l|l|}
\hline RI value & Benign & Malignant & Total \\
\hline$<0.55$ & 11 & 7 & 18 \\
\hline$>0.55$ & 51 & 1 & 52 \\
\hline & 62 & 8 & 70 \\
\hline
\end{tabular}

\section{Statistical analysis of pulsatility index}

Of 70 cases the mean PI value for benign tumor and malignant tumor was 1.2 and 0.67 . The mean $\mathrm{PI}^{16,18,24}$ in the benign and malignant group was significantly different. Based on receiver operating characteristics curve with area under curve of $95 \%$ confidence interval, the best cut off for PI was 0.8 which has a sensitivity of $96 \%$, specificity of $81 \%$,positive predictive value $76 \%$,negative predictive value $97 \%$ and $\mathrm{P}$ value of $<0.05$ was obtained which was statistically significant. By using a previously proposed cut off value for PI of 1.0 with a value less than this considered indicative of malignancy, the sensitivity and specificity in our population was $96.3 \%$ and $77.27 \%$ (Table 7).

Table 7: PI values of benign and malignant tumors.

\begin{tabular}{|l|c|c|c|}
\hline PI value & Benign & Malignant & Total \\
\hline$<0.8$ & 21 & 7 & 28 \\
\hline$>0.8$ & 41 & 1 & 42 \\
\hline & 62 & 8 & 70 \\
\hline
\end{tabular}

Sonography often has a pivotal role in the evaluation of ovarian masses. While grey scale sonography is highly sensitive in identifying ovarian cancer, its diagnostic specificity has been poof. In an attempt to improve the specificity of ultrasound, the use of color Doppler sonography $2,11-13,19,22,25,27$ in addition to grey scale imaging has been proposed. In present study, 70 patients were evaluated using morphologic scoring system $^{14,21,26,28,30}$ proposed by JP Lerner et al and colour flow directed Doppler measurements were taken. In my study the size of the tumour were not taken into account as it was not a significant factor in predicting malignancy. All patients who had bilateral tumours were diagnosed as malignant, while all the benign tumours were unilateral. The menopausal status was a significant factor as $65 \%$ of the patients with carcinoma were postmenopausal. The optimal cut off point for morphologic score in my study is 4 and for RI and PI it is 0.55 and 0.8 respectively.

\section{CONCLUSION}

In summary, the resistance to flow measurements obtained by Doppler had a higher sensitivity and specificity compared to the morphologic scoring system 
in differentiating benign and malignant ovarian masses. The specificity of the scoring system was hampered by many benign masses that had high scores. If the above modalities are combined, malignancy can be ruled out in many masses that are benign by histopathology but nevertheless appear malignant on ultrasound and will guide the management protocols. The combination of morphological score and Doppler measurements improved the specificity and positive predictive value for differentiating benign and malignant ovarian masses.

1. The combination of ultrasound and Doppler values is better in differentiating benign from malignant ovarian masses.

2. The cut off point for ultrasound guided morphologic scoring system was 4 and Doppler velocimetry for benign and malignant ovarian masses was a RI of 0.55 and PI of 0.8 .

\section{ACKNOWLEDGEMENTS}

Authors are gratefully acknowledging and express his sincere thanks to their Dean, HOD (Department of $\mathrm{O}$ and G), Thanjavur Medical College and Hospital, Thanjavur, India for allowing him to do this study and utilizing the Institutional facilities. Authors would also like to thank all the medical and para medical staffs who have helped me to complete this study. A special thanks to all the patients who willingly co-operated and participated in this study.

\section{Funding: No funding sources}

Conflict of interest: None declared

Ethical approval: The study was approved by the Institutional Ethics Committee

\section{REFERENCES}

1. Finkler NJ, Benacerrat B, Lavin PT, wokcie chowskic, Knapp RC, Comparison of serum Ca 125, clinical impression and ultrasound in the preoperative evaluation of ovarian masses. Obset Gynecol. 1988;72;659-64.

2. Bourne T, Campbell S, Steer C, whitehead MI, Collins WP, Transvaginal color flow imaging a possible new screening technique for ovarian cancer. Br Med J. 1989;299:1367-70.

3. Granberg S, Willand M, Jansson I, Macroscopic characterization of ovarian tumors and the relation to histological diagnosis criteria to be used for ultrasound evaluation. Gynecol Oncol. 1989;35:13944.

4. Kounings PP. Campbell K, Mishell DR, Grimes DA, Relative recognition of primary ovarian neoplasia: A 10 year review. Obset Gynecol. 1989:921-6.

5. Campbell S, Royston P, Bhan V. Detection of ovarian malignancy by TAS. BMJ. 1990;390:166373.

6. Einhorn N, Bast RC Jr, Knapp RC. Prospective evaluation of ultrasound and serum of Cal25 in patients with ovarian tumors. Obset Gynecol. 1990:67-414.

7. Fleisher AC, Entman SS. Sonographic evaluation of the ovary and related disorders. Diagnostic ultrasound applied to obstetrics and gynecology, $4^{\text {th }}$ edition. 2014.

8. Jacobs J. A risk of malignancy index incorporation ultrasound and menopausal status for the accurate preoperative diagnosis of ovarian cancer. Br J Obset Gynecol. 1990;97:922-9.

9. Kujat A, Predanic M. New Scoring system for prediction of malignancy based on transvaginal color Doppler sonography. ultrasound Med. 1990.

10. Van Nagell JR, Jr Higgins RV, Donaldson ES. TVS as a screening method for ovarian cancer. A report of the $1^{\text {st }}$ thousand cases screened. Cancer. 1990;65:573-7.

11. Fleisher AC, Rogers WH, Rao BK et al. Transvaginal color Doppler sonography and ovarian masses with pathologic correlation. Obste Gynecol. 1991:275-278.

12. Fleischer AC, Rogers WH, Rao BK et al assessment of ovarian tumor vascularity with transvaginal color Doppler sonography. J Ultrasound Med. 1991;10:563-8.

13. Kurak A, Zalud I, Afirevic Z. Evaluation of adneral masses by transvaginal color ultrasound $\mathrm{J}$ ultrasound Med. 1991;10:295-7.

14. Sasonne AM, Timor - Tritsch IE, Arterr A, Wisthoff C, Warren WB. Transvaginal sonography charact of ovarian disease evaluation of a new scoring system to predict malignancy. Obset. Gynecol. 1991:70-76.

15. Westhoff $\mathrm{C}$, Randall Mc. Ovarian ca screening potential effect on mortality Am J Gynecol. 1991;165;502-5.

16. Weiner Z, Thaler I, Beck D, Rotterm S, Deutsch M, Brandees JM. Differentiating malignant from benign ovarian tumours with TVS color flow imaging Obset Gynecol. 1992;79;159-162.

17. Tekay A, Jeupplia P, Validity of PI and RI in classification of adnexal masses with TVS color Doppler USG ultrasound obsetet gynecol. 1992;2:338-44.

18. Kawai M, Kano T, Kikkawa F, Maeda O, Oguchi F, Transvaginal Doppler ultrasound with color flow imaging in detection ovarian cancer. Obset gynecol. 1992;79:163-7.

19. Hata K, Hata T, Manabe A, Sugimura K, Kitao M. A critical of transvaginal Doppler studies transvaginal sonography and magnetic resonance imaging and $\mathrm{Ca}$ 125 in detecting ovarian tumors. GYMECP. 1992;80:922-6.

20. Davies AP, Jacobs I, Woolas R, Fish A, Oram D. The adnexal mass: Benign or malignant? Evalution of a risk of malignancy index. Br J Obtet Gynecol. 1993;100:927-31.

21. Depriest PD, Shenson BS, Frient A. A morphology index based on sonographic findings in ovarian cancer. Gynecol Oncol. 1993;51:7-11. 
22. Fleisher AC, Rogers WH, Keppic DM, Williams LL, Jones HW. Color Doppler sonography of ovarian masses; a multiparameter analysis. J. Ultrasound Med. 1993;12:41-8.

23. Granberg S, Relationship of macroscopic appearance histologic features of ovarian tumors. Clinical Obstetrics and Gynaecology. 1993;26:363-75.

24. Jacobs I, Davies AP, Stabsle I. Prevalence screening for ovarian cancer in postmenopausal women by $\mathrm{Ca}$ 125 measurement and ultrasound. BMJ. 1993;306:1030-4.

25. Timor - Tritch H. Lerner JP, Monteagudo A, Santos R. TVS characterization of ovarian masses by means of color flow directed Doppler measurements and a morphologic scoring system. Am. J. Obstet Gynocol. 1993;163:909-13.

26. Lerner J, Timor Tritsch J, Federman A, Abramovich $\mathrm{G}$, Transvaginal ultrasonographic characterization of ovaraian masses with an improved weighted scoring system. Am. J. Obset. Gynecol. 1994;170:81-6.
27. Valentinb L, Sladkevicius P, Marsul K. Limited contribution of Doppler velocimetry to the Differential diagnosis of extract pelvic tumors. Obstet Gynecol 1994;83:425-33.

28. Botta G, Zarcone R. Transvaginal examination of ovarian masses in premenopausal women. Eur $\mathbf{J}$ Obstet Gynaecol Reprod Bio. 1995;62:27-4L.

29. Tepper R, Altaros M, Zales Y, Sonographic and Doppler charactreristics of ovarian tumor of low malignant potential. J Clin USG. 1997;25(2):57-61.

30. Brown DL, Doubilet PM, Miller FH, Benign and malignant ovarian masses: Selection of the most discriminating grey scale and Doppler sonographic features. 1993.

Cite this article as: Shyamala JM, Padmasekar A. Sonomorphology and colour flow Doppler studies in differentiating between benign and malignant ovarian masses. Int J Reprod Contracept Obstet Gynecol 2017;6:626-30 